\title{
Characterizing Drought in India Using GRACE Observations of Terrestrial Water Storage Deficit ${ }^{\circ}$
}

\author{
DEBANJAN SinHa AND TAJDARUl H. Syed \\ Department of Applied Geology, Indian Institute of Technology (ISM), Dhanbad, India
}

\section{JAMES S. FAMIGLIETTI}

NASA Jet Propulsion Laboratory, California Institute of Technology, Pasadena, and Department of Earth System Science, and Department of Civil and Environmental Engineering, University of California, Irvine, Irvine, California

\author{
JOHN T. REAGER
}

NASA Jet Propulsion Laboratory, California Institute of Technology, Pasadena, California

\author{
REIS C. THOMAS
}

Department of Earth System Science, University of California, Irvine, Irvine, California

(Manuscript received 14 February 2016, in final form 6 October 2016)

\begin{abstract}
Frequent recurrences of drought in India have had major societal, economical, and environmental impacts. While region-specific assessments are abundant, exhaustive appraisal over large spatial scales has been insubstantial. Here a new drought index called Water Storage Deficit Index (WSDI) is devised and analyzed for holistic representation of drought. The crux of the method is the employment of terrestrial water storage (TWS) variations from Gravity Recovery and Climate Experiment (GRACE) for quantification of drought intensity and severity. Drought events in recent times are well identified and quantified using the approach over four homogenous rainfall regions of India over the period from April 2002 to April 2015. Among the four regions, the highest peak deficit of $-158.00 \mathrm{~mm}$ is observed in January 2015 over central India. While the drought of 2002-04 is prominent in peninsular and west-central India, the drought of 2009-10 and 2012-13 is conspicuous in almost all four regions of India. The longest deficit period of 23 months (from February 2009 to December 2010) and the highest severity value of -26.31 are observed in central and northwestern India, respectively. WSDI values show an increasing trend in west-central India $\left(0.07 \mathrm{yr}^{-1}\right)$, indicating recovery from previously existing drought conditions. On the contrary, a decreasing trend in WSDI is observed in northwestern $\left(-0.07 \mathrm{yr}^{-1}\right)$ and central $\left(-0.18 \mathrm{yr}^{-1}\right)$ India. Results demonstrate considerable confidence in the potential of WSDI for robust characterization of drought over large spatial scales.
\end{abstract}

\section{Introduction}

Droughts are recurrent natural hazards with vast socioeconomic repercussions, collectively affecting the lives of millions of people worldwide (Wilhite 2000).

Supplemental information related to this paper is available at the Journals Online website: http://dx.doi.org/10.1175/ JHM-D-16-0047.s1.

Corresponding author e-mail: Tajdarul H. Syed, tsyed.ismu@ gmail.com
The drought of 2002 itself had adversely affected the gross domestic product of India by approximately $1 \%$ (Gadgil et al. 2003). Drought is an obscure phenomenon, owing to the difficulty in observing its onset, extent, and termination, and it is only visible when its devastating effects begin affecting a region (Wilhite 2006; Mo 2011). Even though causes of drought are often imputed to natural phenomena, certain studies indicate humaninduced impacts (Cook et al. 2009; van Dijk et al. 2013).

Owing to its complexity and the multitude of factors affecting it, there exist considerable differences in the definition of drought and in the appropriateness of 
techniques to monitor it. Previous studies on drought have focused on its quantification, assessment, and prediction by using a variety of different indices. A significant number of these previous studies have concentrated on the development of such indices, whereas many have analyzed and compared them regionally (Keyantash and Dracup 2002; Mo 2008; VicenteSerrano et al. 2010b) to determine the index most suitable for drought monitoring. Among the extensive list of drought indices, the Palmer drought severity index (PDSI; Palmer 1965), standardized precipitation index (SPI; McKee et al. 1993), and standardized runoff index (SRI; Shukla and Wood 2008) are most widely used. PDSI is a climatic water balance index developed in order to measure cumulative departure of surface water balance (Dai 2011). Wells et al. (2004) proposed a self-calibrating PDSI (sc_PDSI) substituting fixed values of climatic coefficient $K$ and duration factors (0.897 and 1/3) used by Palmer (1965) with calibrated values, taking into consideration local variations. Further, a number of specialized drought indices have been devised and applied to quantify drought and monitor its progression (Heim 2000, 2002; Keyantash and Dracup 2002; Vicente-Serrano et al. 2010a; Mishra and Singh 2010; Dai 2011; Sivakumar et al. 2011).

Besides, there are numerous studies on determining the causes of drought (e.g., Cook et al. 2007; Hoerling et al. 2014), drought frequency analysis (e.g., Gregory 1989; Ganguli and Reddy 2014; Kwak et al. 2012; Huang et al. 2014), drought onset and recovery (e.g., Mo 2011; Hao and AghaKouchak 2014), and trend analysis (e.g., Rajeevan et al. 2008; Dai 2011, 2013; Damberg and AghaKouchak 2014; Golian et al. 2015). Despite the ramifications and pervasiveness of drought, explicit quantification of drought remains challenging (Keyantash and Dracup 2002).

Even though remote sensing of drought has been mostly restricted to observing vegetation characteristics (e.g., Singh et al. 2003; Mu et al. 2013), utilization of new observations of terrestrial water storage (TWS), by the use of satellite gravimetry, have been proposed recently (e.g., Thomas et al. 2014). In these studies, TWS has either been used to compute indices similar to commonly used approaches such as PDSI (e.g., Yirdaw et al. 2008; Agboma et al. 2009), to constrain land surface model simulations of drought (e.g., Houburg et al. 2012), or to compare with commonly used drought indices over various drought periods (Long et al. 2013; Tang et al. 2014; Zhang et al. 2016).

It is therefore necessary to integrate all the contributing processes in order to obtain a drought index that can be employed consistently over diverse regional settings. For example, while drought is controlled by the spatiotemporal variability of precipitation, its actual onset is dependent on the amount of water stored on and within the land surface that includes snow, surface water, soil moisture, and groundwater. Thus, there is a need for a comprehensive assessment and monitoring of drought in India using a robust index that integrates all forms of water on and beneath the land surface and that also comprises all the aspects of meteorological, agricultural, and hydrological drought. Based on the cognizance that land is an integrator and controller of hydrologic fluxes and vegetation growth, here we utilize land water storage as a comprehensive metric that encompasses the multidimensional definition of drought. However, despite the theoretical advantage of utilizing land water storage for drought characterization, its implementation was restricted because of the nonavailability of reliable estimates. TWS variations from the NASA Gravity Recovery and Climate Experiment (GRACE; Tapley et al. 2004) satellite mission are the first ever quantification of integrated land water storage.

Recently, Thomas et al. (2014) developed the terrestrial water storage deficit (TWSD) approach, using GRACE-based TWS that can specifically quantify when a period of TWS deficit (or drought) begins, when it ends, the instantaneous magnitude of the TWSD, and an overall metric of drought severity. Since GRACE can quantify (Wahr et al. 2004; Syed et al. 2008) TWSD that accounts for all the storage of water on and below Earth's surface, any significant deviations in TWS from its climatological mean will represent anomalously dry or wet (Reager and Famiglietti 2009; Reager et al. 2014) conditions. Thus, the TWSD can be employed as an important new measure for the quantification of drought. Thomas et al. (2014) also used regionally standardized TWSD to explore spatial variations in drought characteristics.

Here we expand upon the work of Thomas et al. (2014) and use monthly deviations of TWS from mean monthly climatology (depicted as normal hydrologic conditions) to investigate temporal aspects of drought within specific regions in India. We call the standardized deviations the Water Storage Deficit Index (WSDI), and we use it to characterize drought intensity and severity for four homogeneous-rainfall-receiving climatic zones: peninsular, west-central, northwestern, and central India (Fig. 1). Our primary objective here is to continue the development of a robust index that integrates various aspects of drought and that can be used continuously over large climatic regions as well as large river basins. More precisely, we aim to 1) estimate the regional TWS deviations from normal hydrologic conditions; 2) compute monthly WSDI and employ it as a tool to characterize drought in India and also to understand its spatiotemporal variability; and 3) compare WSDI and other commonly 


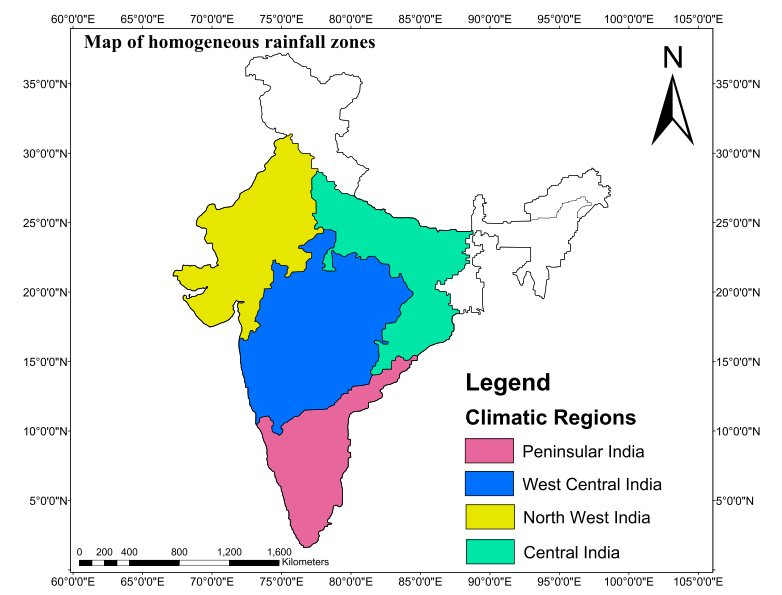

FIG. 1. Study area map of homogeneous rainfall zones of India. Pink area denotes peninsular India, blue area marks west-central India, yellow area denotes northwestern India, and green area represents central India.

used drought indices like PDSI, SPI, and standardized precipitation evapotranspiration index (SPEI).

\section{Drought characterization in India}

The Indian subcontinent is dominated by the tropical monsoon, and the entire region is characterized by disparity in rainfall, both in terms of quantity and distribution. On average, $28 \%$ of the geographical area of India is vulnerable to droughts (Samra 2004) and about 1.07 million $\mathrm{km}^{2}$ are impacted, to varying degrees, by water stress and drought conditions (Mishra et al. 2009). Repeated occurrences of severe droughts have had disastrous consequences in various states, almost every year. India has experienced roughly 24 largescale droughts between 1891 and 2012, with increasing frequencies during the periods 1891-1920, 1965-90, and 1999-2012 (NRAA 2013). The conditions are further exacerbated by increases in the demand for freshwater due to population growth, accompanied by rising living standards and growing industrialization (Mishra et al. 2009).

There are numerous studies that focused on various aspects of drought in India. While Parthasarathy et al. (1987) adopted the criterion of percentage of rainfall departures from normal, Bhalme and Mooley (1980) used the amount and duration of monsoon rainfall to develop the drought area index for the identification of drought over the meteorological subdivisions of India. On the contrary, Naresh Kumar et al. (2009), Bhuiyan et al. (2006), and Jain et al. (2010) utilized SPI for drought characterization over various regions of India. Further, Mishra and Singh (2009) emphasized drought severity-area-frequency changes due to climate change scenarios and compared them with historical droughts for the Kansabati River basin in India. Pandey and Ramasastri (2001) attempted to evaluate the relationship between various climatic parameters (precipitation and evapotranspiration) and drought frequency. Besides, some of the studies had also assessed the role of teleconnection patterns behind drought occurrences over India (Gadgil et al. 2003; Sikka 2003; Francis and Gadgil 2010; Neena et al. 2011). However, most of the studies on drought characterization over India are region specific and are often entirely dependent on rainfall data (Chowdhury et al. 1989; Sinha Ray and Shewale 2001; Guhathakurta 2003). Despite this focus, there remains a clear lack of comprehensive assessment and holistic characterization of drought in contiguous India.

The SPI has been used more extensively for drought analysis compared to the PDSI in India. Studies involving the SPI included drought forecasting (Mishra and Desai 2005a; Mishra et al. 2007), frequency analysis (Mishra et al. 2009), spatiotemporal analysis (Mishra and Desai 2005b; Mishra and Singh 2009), and climate impact studies (Mishra and Singh 2009). Despite their wide applicability, both these indices have some major limitations. SPI values may show discrepancy due to changes in shape and scale parameters of the gamma distribution function when different lengths of precipitation record are involved. Similarly, the PDSI is recognized to have limitations owing to its complex and empirical derivation and because its underlying computation is based on the climate of the midwestern United States (Keyantash and Dracup 2002). The PDSI also assumes that all precipitation is rain, consequently producing erratic values for winter months and at higher altitudes. Furthermore, the PDSI considers that runoff only occurs after all soil layers have become saturated, leading to an underestimation of runoff.

\section{Data}

\section{a. Terrestrial water storage anomaly from GRACE}

Since its launch in 2002, GRACE (Tapley et al. 2004) satellites have accurately detected gravity variations induced by the changes in the TWS column owing to various hydrological processes. TWS includes all forms of water stored above and underneath the land surface, which constitutes snow, surface water, soil moisture, and groundwater. Imperatively, the atmospheric and oceanic contributions with the addition of third-body perturbations and solid Earth tides are eliminated from the GRACE data solutions (Wahr et al. 2004; Chen et al. 2005a,b). Since GRACE satellites lack the vertical resolution to distinguish changes in the various components 
of the hydrosphere separately, they can only recognize the variations in column-integrated water mass. Global TWS estimates derived from temporal gravity field variations, observed by the GRACE satellites, require postprocessing techniques for scaling, smoothing, truncation, and removing correlated errors and are thoroughly discussed in Tapley et al. (2004), Swenson and Wahr (2006), and Landerer and Swenson (2012).

GRACE-derived gravimetric measurements have been widely utilized in determining various hydrologic estimates like groundwater storage changes (Rodell et al. 2009; Tiwari et al. 2009; Famiglietti et al. 2011; Voss et al. 2013; Castle et al. 2014), groundwater stress (Richey et al. 2015a,b), changes in TWS (Strassberg et al. 2007; Syed et al. 2008; Soni and Syed 2015), variations in evapotranspiration (Rodell et al. 2004, 2011; Zeng et al. 2012; Syed et al. 2014), freshwater discharge (Syed et al. 2007, 2009, 2010), regional flood potential (Reager and Famiglietti 2009; Reager et al. 2014), changes in runoff (Lorenz et al. 2014), and characterization of hydrologic drought (Yirdaw et al. 2008; Chen et al. 2009; Leblanc et al. 2009; Frappart et al. 2012; Long et al. 2013; Thomas et al. 2014).

Here we use the most recent release of monthly GRACE land water storage data (RL05) produced by the Center for Space Research (CSR) at the University of Texas at Austin, gridded and scaled by the NASA Jet Propulsion Laboratory (JPL) following Landerer and Swenson (2012). We use 157 monthly estimates of water storage variations extending from April 2002 to April 2015. Values for a few missing months are replaced by the climatological median for that calendar month before employing it for further estimates. Postprocessing of GRACE level 3 data is required in order to apply the geophysical corrections to the GRACE data. A glacial isostatic adjustment (GIA) correction has been applied to remove the gravity effect that emerged from perpetual isostatic adjustment of Earth's crust and mantle. The effects of correlated errors have also been minimized by the application of a destriping filter (Swenson and Wahr 2006). To produce the spatial maps of terrestrial water storage anomaly (TWSA) in terms of equivalent water thickness, the spherical harmonic coefficients have been truncated to $60^{\circ}$, smoothed with a $300-\mathrm{km}$ Gaussian averaging kernel, and subsequently expanded to regular grids. All the aforementioned postprocessing of the GRACE dataset induces surface mass variations at small spatial scales that tend to attenuate. The scaling factor (available at http://grace.jpl.nasa.gov/data/getdata/monthly-mass-grids-land) has been applied to every grid to restore this signal attenuation. Integrated effects of Gaussian filtering, destriping, and truncating the harmonical series cause errors in GRACE signals that can be estimated from hydrological models. Leakage error (after filtering and scaling) for each and every grid cell is provided on the GRACE website (http:// grace.jpl.nasa.gov/data/get-data/monthly-mass-gridsland). The GRACE dataset used here includes all the latest data improvement techniques developed so far (Landerer and Swenson 2012).

\section{b. Self-calibrated PDSI}

Palmer (1965) formulated the PDSI with an objective to assess the deviations in surface water balance. The PDSI integrates precursory and contemporary moisture supply (precipitation $P$ ) and demand [potential evapotranspiration (PE)] into a hydrological accounting system, which includes a two-layer buckettype model for soil moisture calculations. Central to the estimation of PDSI is the difference between the actual precipitation and the measure of precipitation needed to hold an appropriate soil moisture level for the same month (Preq). To improve spatial comparability, Wells et al. (2004) propounded a self-calibrating PDSI (i.e., sc_PDSI) by replacing the empirically derived fixed values of the climatic characteristic (i.e., $K$ ) and the duration factors $(0.897$ and $1 / 3)$ used by Palmer (1965), based on data from the central United States, with values automatically calculated using historical climatic data of a specific region. Global grids $\left(2.5^{\circ} \times\right.$ $2.5^{\circ}$ ) of monthly self-calibrated PDSI data (http:// www.esrl.noaa.gov/psd) are used here for the period from April 2002 to December 2010. The dataset utilized to compute self-calibrated PDSI and the methodology applied is elaborated in Dai et al. (2004) and Dai (2011).

\section{c. $S P I$}

The SPI (McKee et al. 1993) is fundamentally a meteorological drought index calculated using precipitation amounts at different time scales (months). To compute the SPI, a Gamma distribution is first fitted to the precipitation values during the time (month) period. Afterward, the Gamma distribution is converted to a Gaussian distribution (standard normal distribution with mean of zero and variance of one), which gives the value of SPI for the time scale used. In this study, a monthly SPI dataset is developed using the Global Precipitation Climatology Project (GPCP) monthly precipitation analysis (version 2.2; Adler et al. 2003). This precipitation dataset is a combined analysis of satellite and gauge-based measurements, for the period from 1979 to the present, available as $2.5^{\circ} \times 2.5^{\circ}$ global grids. Information contributed from various platforms is merged into the final product, taking advantage of the strengths of each data type. 


\section{d. SPEI}

The SPEI is a multiscalar drought index like the SPI, based on climatic water balance (Vicente-Serrano et al. 2010a,b; Beguería et al. 2010). The SPEI has been calculated using the global $0.5^{\circ}$ gridded Climatic Research Unit Time Series, version 3 (CRU TS3), monthly precipitation dataset (available at http://badc.nerc.ac.uk/browse/badc/cru/ data) and potential evapotranspiration estimated using Thornthwaite's method. Subsequently, a log-logistic distribution is fitted to determine SPEI values for the time period used. The SPEI dataset used here is obtained from the Institutional Repository of the Spanish National Research Council (CSIC; https://digital.csic.es) covering the time period from April 2002 to December 2013.

\section{e. SRI}

SRI is a multivariate hydrological drought index that demonstrates the potential of simulated runoff for identifying drought. SRI is computed by fitting a lognormal distribution function to runoff estimates (Shukla and Wood 2008). SRI is very similar to SPI and is also dimensionless. In this study we have used the Noah, version 2, dataset from GLDAS to compute SRI for the four climatic zones of India.

\section{Methods}

We produced spatially averaged GRACE TWSA monthly time series for each of the four climatic regions shown in Fig. 1. For each of the regions, mean monthly climatology is computed by averaging the GRACEderived TWSA data for each calendar month within the span of a 13-yr period (from April 2002 to April 2015) (e.g., average of 13 values for April, May, etc.). The climatology of TWSA $(\mathrm{mm})$ serves as the standard for quantification of deviations from normal hydrological conditions for that particular calendar month. The mean monthly climatology also helps in ascertaining the nature of seasonality and to identify the occurrence of aberrant variations in a particular region. Despite the fact that long-term data are desirable to compute the climatology, because of the limited period of availability of GRACE data, we calculate the monthly climatology with 157 months of available data.

The residual time series, obtained by subtracting the regional climatology of TWSA from the monthly GRACE solutions (TWSA) for all the four climatic regions, illustrate digressions from the usual annual cycle or normal hydrologic conditions (represented by climatology of TWSA). Therefore, negative residuals are indicating deficits in land water storage compared to its climatologic mean, whereas positive residuals signify surplus water storage. The WSDI is computed as
TABLE 1. Characterization of drought intensity by WSDI.

\begin{tabular}{ll}
\hline \hline \multicolumn{1}{c}{ WSDI value } & \multicolumn{1}{c}{ Drought category } \\
\hline From 3.0 to 4.0 & Extremely wet conditions \\
From 2.0 to 3.0 & Severe wet conditions \\
From 1.0 to 2.0 & Moderately wet conditions \\
From -0.99 to 0.99 & Near-normal conditions \\
From -1.0 to -2.0 & Moderate drought conditions \\
From -2.0 to -3.0 & Severe drought conditions \\
From -3.0 to -4.0 & Extreme drought conditions \\
\hline
\end{tabular}

$$
\begin{aligned}
T_{i}^{\mathrm{res}} & =\mathrm{TWSA}_{i}-\mathrm{TWSA}_{j}^{\text {clim }} \text { and } \\
\mathrm{WSDI}_{i} & =\frac{T_{i}^{\mathrm{res}}-\mu_{T_{\mathrm{res}}}}{\sigma_{T^{\mathrm{res}}}},
\end{aligned}
$$

where $T$ stands for the residual time series and $\mu$ and $\sigma$ stand for mean and standard deviation of the time series, respectively. The superscripts "res" and "clim" denote residual and mean monthly climatology of TWSA. The subscript $i$ varies from 1 to 157 (i.e., the total number of months in the study period) and $j$ varies from 1 to 12 , depicting corresponding calendar month. Note that the negative sign of WSDI indicates drought conditions while its magnitude represents the intensity. The categorization of drought intensity, computed using the standard deviation of WSDI time series, is detailed in Table 1.

Additionally, a trend analysis is performed on the derived WSDI for each of the climatic regions. A modified Mann-Kendall trend test (Hamed and Rao 1998) is applied to detect changes in the time series of WSDI. Since autocorrelation exists in most observed data, the empirical significance levels of the trend test are exaggerated compared to the nominal significance levels. Thus, autocorrelation in observed data will result in misinterpretation of trend test results. Hence, a modified Mann-Kendall trend test is selected over the Mann-Kendall trend test (Mann 1945; Kendall 1955) as it is robust in the presence of autocorrelation in the data. Empirical significance levels of the modified test are much more proximate to the nominal significance levels. To use the modified test, a nonparametric trend estimate (Sen 1968) is first deducted from the time series, and the autocorrelation between the ranks of the observations (rank correlation coefficient is a measure of correlation, that is, a number that shows how closely two sets of data are linked) is calculated. Significant autocorrelations at $5 \%$ significance level are then utilized to assess the modified variance of the statistic. Using the variance, the significance value ( $p$ value) of the test is calculated.

While standardized ( $Z$ score) monthly deficits are characterized as drought conditions, its persistence in time is the key to the severity $S$ of damage caused by such an event. Here we define a "drought event" as a 

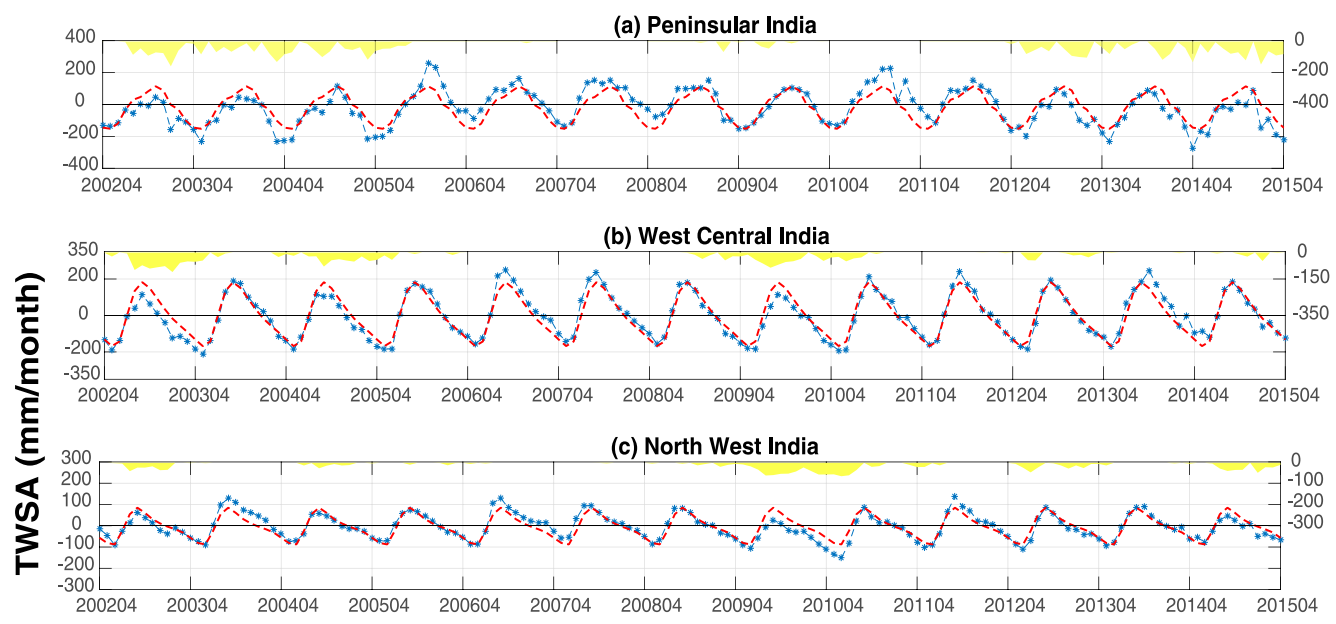

(d) Central India

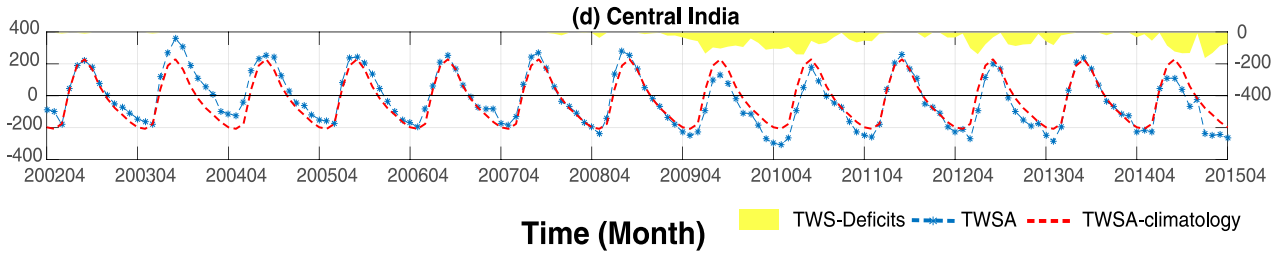

FIG. 2. TWSAs and TWSDs observed by GRACE for each of the four climatic zones of India. Blue dashed lines denote TWSA, red dashed lines denote climatological mean of TWSA for each calendar month, and yellow filled curves denote deficit in TWS.

period over which a negative WSDI persists over three or more consecutive months. The rest of the negative values indicate isolated months of drought condition that have returned to normal or excess water storage conditions within the next month or two. To quantify the joint influence of water storage deficits and their span of occurrence, we computed $S$ for each of the "drought events" from WSDI. Following Thomas et al. (2014) and Keyantash and Dracup (2004), $M$ denotes the magnitude of the monthly negative values of WSDI.

Severity [i.e., $S(t)$ ] is calculated for each drought event as a product of average negative values (deficits) of WSDI [i.e., $M(t)]$ and the number of months [i.e., $T(t)]$ a particular drought event persists (Yevjevich 1967; Thomas et al. 2014). In this regard, the last month of an event is not included for the computation of severity, as it is considered to be the transition between dry and normal spells (Keyantash and Dracup 2004). Once the onset and termination of a drought event has been identified, the severity for an event is calculated by the following equation:

$$
S(t)=M(t) \times T(t) .
$$

Here $t$ denotes the number of drought events, which can vary from 1 to $n$ number of drought events in a specific region. Note that it is only for the purpose of severity analysis of drought events that accumulated values of WSDI are employed. Autocorrelation analysis of TWSA time series have revealed significant serial correlation at time lags of up to two months (Fig. S1 in the supplemental material). Hence, in this study, drought events, considered for severity analysis, are identified by the persistence of negative WSDI values for three or more months. This consideration also supports the idea that isolated monthly negative WSDI values may arise from sudden unusual weather variations and do not qualify as a drought event. Even though the severity of a drought event can only be evaluated after the drought event ends, it can serve as a holistic metric for intercomparison of drought events recognized by other indices.

\section{Results}

\section{a. Estimation of storage deficits}

Figure 2 shows time variations of TWSA (dashed blue line) and its climatology (dashed red line) for each of the four homogenous rainfall regions of India (Fig. 1). The negative differences between the two are referred to here as TWSD and are shown as filled curves (yellow). Deficits in total water storage are observed in all regions during various periods between April 2002 and April 2015. The average and peak values of the TWSD in each of the climatic zones are given in Table 2. To establish the objectivity of the results to GRACE data processing techniques, we have compared (Fig. S2 in 
TABLE 2. Summary of TWSD computed for the water-stressed periods observed over the four homogenous rainfall regions of India.

\begin{tabular}{|c|c|c|c|c|}
\hline Time period & Duration (No. of months) & Average deficit (mm) & Peak deficit (mm) & Peak deficit month \\
\hline \multicolumn{5}{|l|}{ Peninsular India } \\
\hline From Jul 2002 to May 2003 & 11 & -61.30 & -155.40 & Jan 2003 \\
\hline From Jul 2003 to May 2004 & 11 & -63.27 & -128.00 & Mar 2004 \\
\hline From Jul 2004 to Aug 2005 & 14 & -48.44 & -113.70 & Mar 2005 \\
\hline From Jun to Sep 2012 & 4 & -57.09 & -78.84 & Jun 2012 \\
\hline From Nov 2012 to Feb 2013 & 4 & -83.26 & -100.90 & Feb 2013 \\
\hline From Apr to Aug 2013 & 5 & -37.67 & -78.18 & May 2013 \\
\hline From Nov 2013 to Nov 2014 & 13 & -61.78 & -129.30 & Apr 2014 \\
\hline From Jan to Apr 2015 & 4 & -92.47 & -143.90 & Jan 2015 \\
\hline \multicolumn{5}{|l|}{ West-central India } \\
\hline From Jul 2002 to May 2003 & 11 & -65.61 & -107.20 & Jan 2003 \\
\hline From Mar to May 2004 & 3 & -16.95 & -24.55 & Mar 2004 \\
\hline From Jul 2004 to Jun 2005 & 12 & -38.08 & -77.02 & Sep 2004 \\
\hline From Sep to Dec 2008 & 4 & -16.19 & -35.28 & Nov 2008 \\
\hline From Feb to Dec 2009 & 11 & -43.82 & -83.38 & Aug 2009 \\
\hline From Feb to Aug 2010 & 7 & -31.82 & -48.27 & Jun 2010 \\
\hline From Mar to Jul 2012 & 5 & -17.95 & -43.43 & Jul 2012 \\
\hline From Nov 2012 to Mar 2013 & 5 & -13.33 & -26.44 & Feb 2013 \\
\hline From Oct 2014 to Feb 2015 & 5 & -20.04 & -46.64 & Jan 2015 \\
\hline \multicolumn{5}{|l|}{ Northwestern India } \\
\hline From Jun 2002 to Jan 2003 & 6 & -22.71 & -39.22 & Aug 2002 \\
\hline From Jul 2004 to Jan 2005 & 7 & -11.69 & -25.75 & Sep 2004 \\
\hline From Jan to Mar 2006 & 3 & -4.78 & -11.69 & Feb 2006 \\
\hline From Feb 2009 to Aug 2010 & 19 & -38.45 & -63.02 & Jun 2010 \\
\hline From Mar to Jul 2011 & 5 & -12.58 & -20.88 & Apr 2011 \\
\hline From May to Aug 2012 & 4 & -23.53 & -45.02 & Jul 2012 \\
\hline From Oct 2012 to May 2013 & 8 & -12.74 & -27.05 & Dec 2012 \\
\hline From Jul to Nov 2014 & 5 & -27.08 & -38.15 & Sep 2014 \\
\hline From Jan to Apr 2015 & 4 & -24.77 & -47.02 & Jan 2015 \\
\hline \multicolumn{5}{|l|}{ Central India } \\
\hline From Feb 2009 to Dec 2010 & 23 & -74.29 & -135.8 & Aug 2010 \\
\hline From Feb to Jul 2011 & 6 & -34.87 & -10.14 & Mar 2011 \\
\hline From Mar 2012 to Jul 2013 & 17 & -50.11 & -133.8 & Jul 2012 \\
\hline From Apr to Jun 2014 & 3 & -28.52 & -49.35 & Jun 2014 \\
\hline From Aug 2014 to Apr 2015 & 9 & -98.63 & -158.00 & Jan 2015 \\
\hline
\end{tabular}

the supplemental material) TWSA time series used in this study with those obtained from JPL Mascons (http:// grace.jpl.nasa.gov/data/get-data/jpl_global_mascons/) and GRACE Le Groupe de Recherche de Géodésie Spatiale (GRGS; http://grgs.obs-mip.fr/grace).

GRACE-derived TWSD variations in peninsular India show eight deficit periods (Fig. 2a). Most of the periods with major deficits coincide with drought conditions reported in India (NRAA 2013). The period between July 2002 and August 2005 represents the most extensive drought period in this region, although it is interrupted by two intermittent months (June 2003 and June 2004) of surplus in storage. The magnitude of the maximum deficit in this region is $-155.40 \mathrm{~mm}$ recorded in the month of January 2003, which is also the highest in comparison to the other regions.

There are nine instances of storage deficit observed in west-central India (Fig. 2b). The maximum monthly deficit observed in this region is $-107.20 \mathrm{~mm}$ (in January 2003). Similarly, in northwestern India (Fig. 2c), nine events with large deficiency in terrestrial water storage are identified from GRACE observations. A span of 19 months (from February 2009 to August 2010) of continuous deficit is observed in this climatic region with an average deficit of $-38.45 \mathrm{~mm}$ and a peak deficit of $-63.02 \mathrm{~mm}$ in June 2010. Time series of TWSD in central India (Fig. 2d) reveal the longest GRACEidentified water-stressed condition among the areas studied, that is, between February 2009 and December 2010 (23 months), with an average deficit of $-74.29 \mathrm{~mm}$ and a peak magnitude of $-135.8 \mathrm{~mm}$ (in August 2010).

The GRACE-derived TWSD are also consistent with the meteorological droughts reported in the region. Drought occurrences during the period of 2002-04 (Hoyos and Webster 2007) coincide with the major TWSD in peninsular (Fig. 2a) and west-central India (Fig. 2b). The meteorological droughts of 2009-10 (NRAA 2013) are also coincident with the GRACEidentified deficit scenarios in west-central (Fig. 2b), 


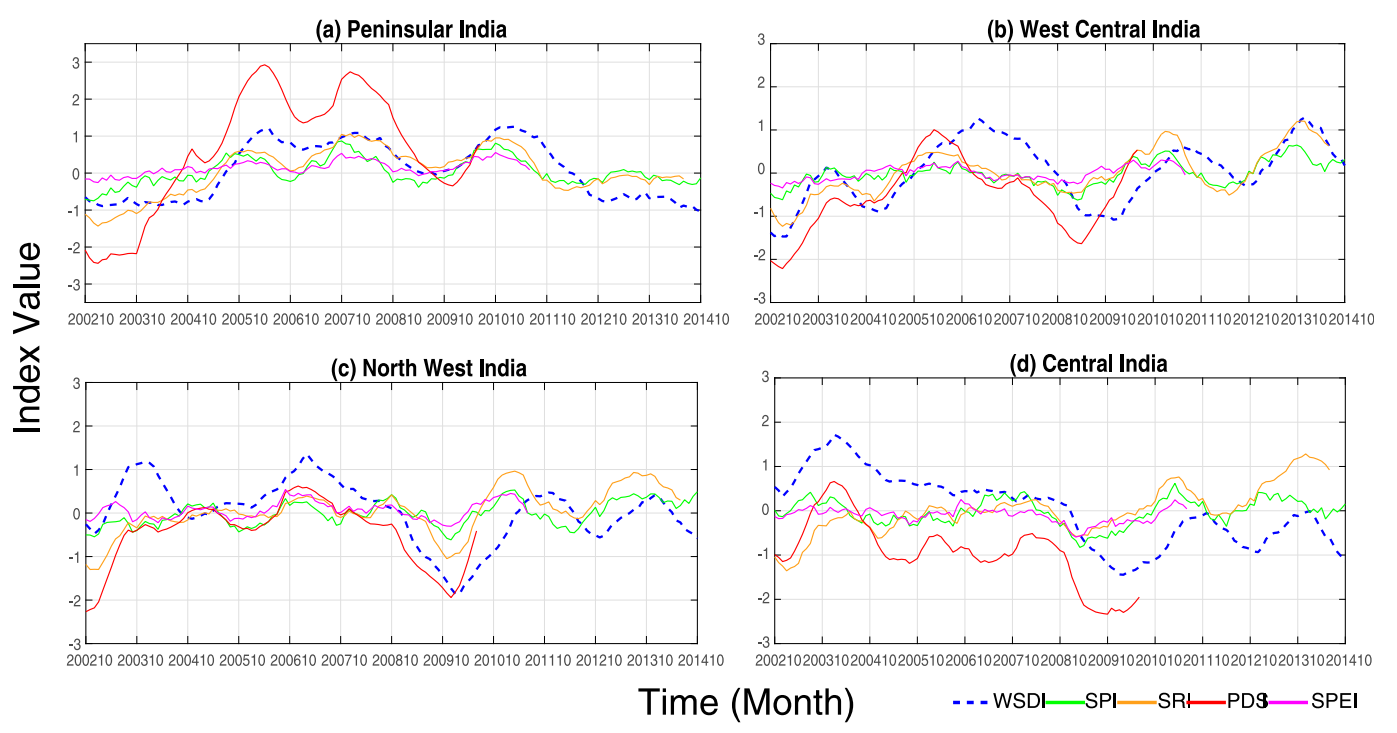

FIG. 3. Comparisons between WSDI and three other drought indices over the four climatic regions of India. Blue dashed lines are WSDI, red solid lines are PDSI, green solid lines are SPI, magenta solid lines are SPEI, and orange solid lines are SRI. A centered 12-month moving-average filter is fitted to each of the time series.

northwestern (Fig. 2c), and central India (Fig. 2d). Deficit periods identified by GRACE other than those two that reported major drought events underscore the potential of GRACE for identifying storage depletion that could not be captured because of the limitations in other commonly used drought metrics and their sole dependence on sparse surface hydrological information (Thomas et al. 2014), particularly in areas where groundwater withdrawals are significant (Famiglietti 2014). Because of variations in regional water management practices, subsurface water storage may be depleted more than surface water storage. Note that GRACE is capable of identifying the deficit in column-integrated TWS, including surface and subsurface water storage that may otherwise not be identified using standard, surface hydrometeorologically based methods.

\section{b. Comparison between WSDI and other commonly used drought indices}

Shown in Fig. 3 are comparisons between time series of WSDI and the four most commonly used drought indices, namely, PDSI, SPI, SPEI, and SRI over the four climatic regions of India. To assess the comparison at interannual scales, a centered 12-month moving average is fitted to each of the time series. The lack of contemporaneity in the utilized datasets restricted the comparison to different time periods. While the PDSI, SPEI, and SRI time series extended through the end of 2010, 2013, and 2014, respectively, SPI and WSDI time series extended until the end of the study period. In Fig. 3, time series of WSDI, SPI, PDSI, SPEI, and SRI are represented by blue, green, red, magenta, and orange lines, respectively. The observed behavior of the WSDI and its response to the climatic abnormalities agrees reasonably well with the other indices explored. However, since WSDI is formulated using residual time series [Eq. (2)], differences in behavior among the indices are expected. SPI and SPEI are more responsive to the rate of precipitation and evapotranspiration; as a result, higher magnitudes of fluctuations are observed in the time series of SPI and SPEI that consequently lead to poor correlation with WSDI. On the contrary, SRI is rather incessant with relatively lowerfrequency variations, which are better correlated with WSDI in comparison to SPI and SPEI (Table 3). The rationale behind this is the greater dependence of runoff generation on land moisture characteristics. The correlation coefficients reveal a fair correlation between SRI and WSDI. However, it is important to note that in all four climatic zones the magnitude of PDSI is greater than that of WSDI, even though there is a high degree of compatibility in the timing of the drought events as represented by both the indices. For example, in all four climatic zones of India (Fig. 3), PDSI-identified droughts of 2002-03 and 2009-10 show acute conditions in comparison to WSDI. Similarly, in central India during 2002-03, WSDI shows wet conditions while PDSI values indicate moderate drought condition. At the same time, temporal variations of WSDI are best correlated with PDSI. Estimated values of the correlation coefficient $r$ between the WSDI and the PDSI in peninsular, west-central, northwestern, and central India are $0.76,0.55,0.48$, and 0.70 , respectively. Shown in Table 3 are the estimates of correlation between WSDI and other independent drought indices. 
TABLE 3. Correlation matrix of drought indices computed for the four homogenous rainfall regions of India.

\begin{tabular}{|c|c|c|c|c|c|}
\hline & WSDI & PDSI & SPI & SPEI & SRI \\
\hline \multicolumn{6}{|c|}{ Peninsular India } \\
\hline WSDI & 1 & & & & \\
\hline PDSI & 0.76 & 1 & & & \\
\hline SPI & 0.33 & 0.48 & 1 & & \\
\hline SPEI & 0.27 & 0.43 & 0.80 & 1 & \\
\hline SRI & 0.56 & 0.71 & 0.48 & 0.41 & 1 \\
\hline \multicolumn{6}{|c|}{ West-central India } \\
\hline WSDI & 1 & & & & \\
\hline PDSI & 0.55 & 1 & & & \\
\hline SPI & 0.21 & 0.57 & 1 & & \\
\hline SPEI & 0.10 & 0.53 & 0.85 & 1 & \\
\hline SRI & 0.48 & 0.68 & 0.51 & 0.49 & 1 \\
\hline \multicolumn{6}{|c|}{ Northwestern India } \\
\hline WSDI & 1 & & & & \\
\hline PDSI & 0.48 & 1 & & & \\
\hline SPI & 0.08 & 0.55 & 1 & & \\
\hline SPEI & 0.13 & 0.55 & 0.81 & 1 & \\
\hline SRI & 0.37 & 0.80 & 0.65 & 0.55 & 1 \\
\hline \multicolumn{6}{|c|}{ Central India } \\
\hline WSDI & 1 & & & & \\
\hline PDSI & 0.70 & 1 & & & \\
\hline SPI & 0.10 & 0.50 & 1 & & \\
\hline SPEI & 0.12 & 0.42 & 0.71 & 1 & \\
\hline SRI & -0.07 & 0.32 & 0.26 & 0.26 & 1 \\
\hline
\end{tabular}

The inconsistencies noted in Fig. 3 between the drought indices are perhaps best explained by the fundamental differences in the type of data and method used in the computation of the indices. The commonly used drought indices have some prominent constraints in their formulation. While SPI and SRI are computed solely based on precipitation and runoff estimates, SPEI is based on precipitation and evapotranspiration. But the computation of PDSI involves a series of processes involving various water balance parameters. This is likely the reason behind the good correlation between WSDI and PDSI. Furthermore, PDSI is computed using the potential values of the variables utilized, that is, it uses the maximum possible values of each variable. Hence, there is a possibility of exaggerating the hydrologic conditions, which may be different in reality. On the contrary, WSDI accounts for all the changes in storage due to various hydrological fluxes and is able to quantify the actual amount of water [equivalent thickness $(\mathrm{mm})$ ] missing from the storage. Thus, it is expected to deliver better results in the context of explaining the actual hydrological condition of a region. The comparison also confirms the existence of the two most conspicuous drought events reported in India on the basis of WSDI, during 2002-04 and 2009-10.

\section{c. WSDI analysis and severity computation}

Figure 4 illustrates the severity of each drought event identified by WSDI. Only the deficit periods sustaining for three or more consecutive months are considered for severity analysis and are listed in Table 4 . The prolonged period of dryness varies differently for each climatic region. In Fig. 4, the stem plot (blue lines) stands for the severity for each drought event. The value of severity [Eq. (3)] for each of the events is represented alongside each event (boldface numbers). The severity for each event in the four climatic zones is calculated to quantify the intensity of drought events within the period of 157 months, that is, from April 2002 to April 2015.

Among the eight drought events observed in peninsular India (Fig. 4a), the most extensive deficit period, between July 2004 and August 2005 (14 months), is estimated to have a severity of -9.83 . Similarly, drought events with severities of -8.98 and -9.50 , sustained over a period of 11 months, are observed and coincide with the reported drought events of 2002-03 and 2003-04, respectively. West-central India (Fig. 4b) experienced the longest (i.e., 12 months) water-stressed conditions between July 2004 and June 2005 with a severity of -10.73 . Two other occurrences of 11 months each are identified with total severities of -17.44 and -11.50 , respectively. The only major drought event observed in northwestern India (Fig. 4c) occurred from February 2009 to August 2010 with a total severity of -26.31 . Among the four regions studied here, the highest magnitude of total severity $(-26.31)$ is observed in northwestern India (Fig. 4c). This drought event persisted for a period of 19 months (from February 2009 to July 2010). The longest dry spell among the four regions existed for a period of 23 months (from February 2009 to December 2010), with a severity of -26.14 observed in central India (Fig. 4d). Additionally, there are numerous occurrences of minor droughts or temporary periods of dryness (with low severity values) in all four climatic regions. Sometimes, these minor droughts are coincident in time, such as those between 2012 and 2013, indicating large-scale existence of drought conditions.

Figure 5 represents the time series of WSDI (blue solid lines) along with the fitted trend lines (red dashed lines) for each of the four climatic zones of India. The WSDI-identified drought events are marked in yellow for each of the four climatic regions. Figure 5a shows two isolated but prolonged periods of drought in peninsular India, in the range from moderate to severe intensity, from July 2002 to August 2005 and from June 2012 to April 2015. In between, an almost continuous, nearnormal to wet spell prevailed in the region. No significant trend in WSDI values is observed in this region. The estimates of trend and its significance values based on the modified Mann-Kendall test over the four homogenous rainfall regions are given in Table 5. In westcentral India (Fig. 5b), three significant dry spells are observed from July 2002 to May 2003, July 2004 to June 


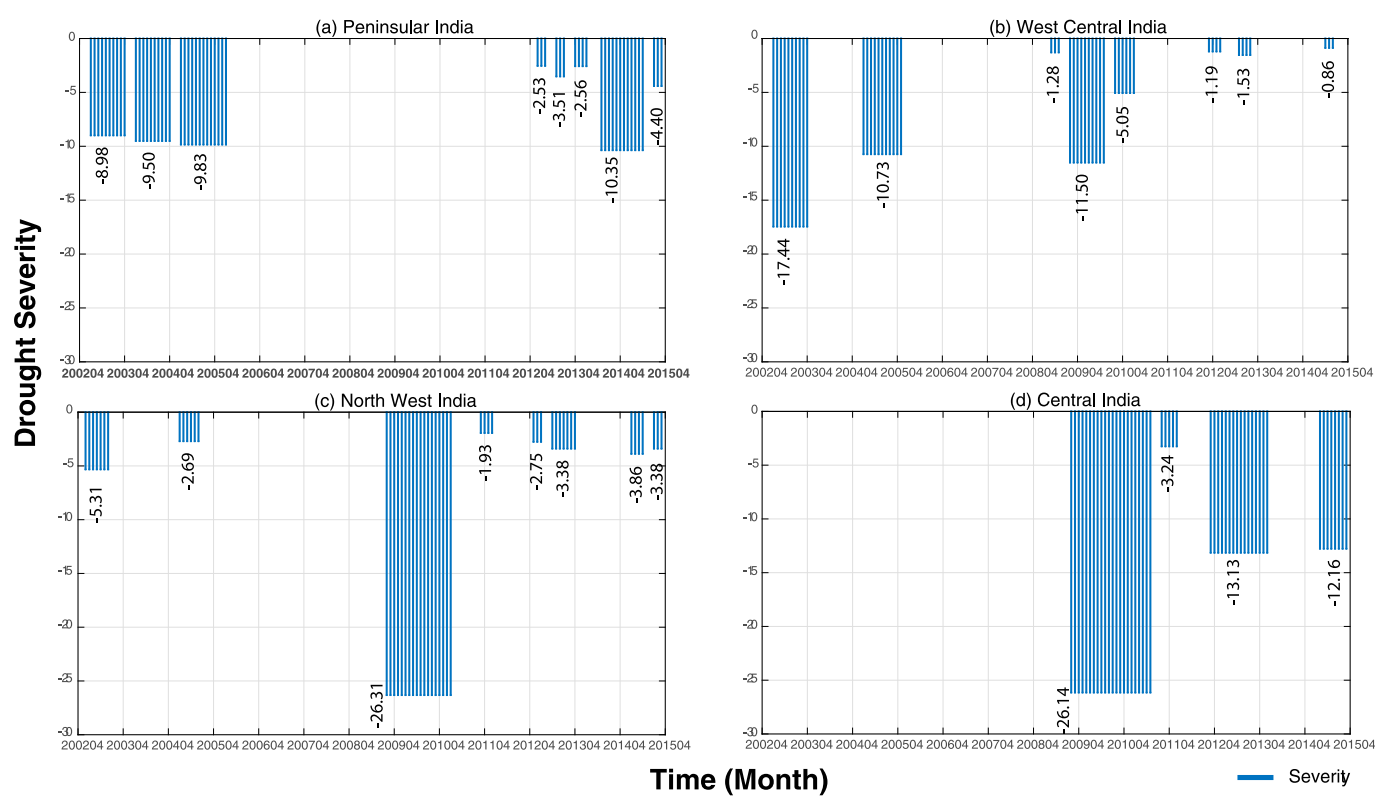

FIG. 4. Estimates of drought severity computed for each of the "drought events" identified by WSDI in each of the four climatic zones of India. The stem plot (blue lines) stands for the severity for each drought event.

2005, and February to December 2009. With reference to WSDI, these drought events are characterized as from moderate to severe, near-normal to moderate, and moderate to severe, respectively. Here, a rising trend $\left(0.07 \mathrm{yr}^{-1}\right)$ is observed, indicating transition from waterdeficient to water-sufficient conditions. Similarly, a single drought event, extending over 19 months (from February 2009 to August 2010), is noted in northwestern India (Fig. 5c) compared to two such significant drought events in central India (Fig. 5d) during the entire study period of 157 months. The drought events identified in central India prevailing between July 2004 and January 2005 and between October 2012 and May 2013 are from near-normal to moderate and from moderate to severe drought intensities. In spite of some intermittent wet spells, an overall diminishing trend of $-0.07 \mathrm{yr}^{-1}\left(-0.18 \mathrm{yr}^{-1}\right)$ observed in northwestern (central) India is evidence of the intensifying water-stressed conditions prevalent in the regions. Since GRACE is able to detect water mass loss in any form, including groundwater withdrawals, it is likely that the negative trends observed in northwestern and central India can, in part, include signals related to anthropogenic extraction of groundwater. Hence, the implicit representation of anthropogenic exaggeration of drought conditions enables WSDI with the capacity to represent a more realistic and physically meaningful characterization of drought.

\section{Discussion and conclusions}

In this study, observations of TWSA from GRACE satellites are utilized to compute WSDI as a robust metric for drought characterization over large spatial scales. Recent drought events over four homogenous rainfall regions of India are quantified and analyzed for a period of 157 months (from April 2002 to April 2015). Also presented are the peak magnitude and the severity of the identified drought events.

In essence, the methodology involves the transformation of GRACE-based TWSD to WSDI, which is represented here as a comprehensive metric for drought monitoring and analysis. Although used earlier as a volumetric representation of deficit, the derived WSDI has certain advantages over the other, the most important one being the limitation to make comparative assessment of drought because of the dependence on geographical area for volumetric quantification of deficit. For example, larger volumetric deficit in a larger area does not necessarily indicate greater intensity of drought compared to a relatively smaller volumetric deficit in a smaller area, since larger areas will produce larger volumetric deficit compared to smaller areas. Further, the index formulation enables suitable comparison with other available indices computed for the study regions. Overall, the methodology provides simple yet robust assessment of drought over large spatial scales.

The concept of the utilization of TWSD to compute WSDI is further corroborated by the fact that TWSA is an integrated effect of various surface and subsurface hydrologic processes. Moreover, below-normal rainfall may not be an adequate representation of a prevailing drought condition if there is ample terrestrial storage of water to compensate for the deficit. Similarly, despite 
TABLE 4. Summary of drought severity and their magnitude and duration computed from WSDI for the identified "drought events" over the four homogenous rainfall regions of India.

\begin{tabular}{|c|c|c|c|}
\hline Time period & Duration (No. of months) & Average deficit & Severity \\
\hline \multicolumn{4}{|l|}{ Peninsular India } \\
\hline From Jul 2002 to May 2003 & 11 & -0.90 & -8.98 \\
\hline From Jul 2003 to May 2004 & 11 & -0.95 & -9.50 \\
\hline From Jul 2004 to Aug 2005 & 14 & -0.76 & -9.83 \\
\hline From Jun to Sep 2012 & 4 & -0.84 & -2.53 \\
\hline From Nov 2012 to Feb 2013 & 4 & -1.17 & -3.51 \\
\hline From Apr to Aug 2013 & 5 & -0.64 & -2.56 \\
\hline From Nov 2013 to Nov 2014 & 13 & -0.86 & -10.35 \\
\hline From Jan to Apr 2015 & 4 & -1.47 & -4.40 \\
\hline \multicolumn{4}{|l|}{ West-central India } \\
\hline From Jul 2002 to May 2003 & 11 & -1.74 & -17.44 \\
\hline From Jul 2004 to Jun 2005 & 12 & -0.98 & -10.73 \\
\hline From Sep to Dec 2008 & 4 & -0.43 & -1.28 \\
\hline From Feb to Dec 2009 & 11 & -1.15 & -11.50 \\
\hline From Feb to Aug 2010 & 7 & -0.84 & -5.05 \\
\hline From Mar to Jul 2012 & 5 & -0.30 & -1.19 \\
\hline From Nov 2012 to Mar 2013 & 5 & -0.38 & -1.53 \\
\hline From Oct 2014 to Feb 2015 & 5 & -0.29 & -0.86 \\
\hline \multicolumn{4}{|l|}{ Northwestern India } \\
\hline From Jun 2002 to Jan 2003 & 6 & -0.76 & -5.31 \\
\hline From Jul 2004 to Jan 2005 & 7 & -0.45 & -2.69 \\
\hline From Feb 2009 to Aug 2010 & 19 & -1.46 & -26.31 \\
\hline From Mar to Jul 2011 & 5 & 0.48 & -1.93 \\
\hline From May to Aug 2012 & 4 & -0.92 & -2.75 \\
\hline From Oct 2012 to May 2013 & 8 & -0.48 & -3.38 \\
\hline From Jul to Nov 2014 & 5 & -0.97 & -3.86 \\
\hline From Jan to Apr 2015 & 4 & -1.13 & -3.38 \\
\hline \multicolumn{4}{|l|}{ Central India } \\
\hline From Feb 2009 to Dec 2010 & 23 & -1.19 & -26.14 \\
\hline From Feb to Jul 2011 & 6 & -0.63 & -3.24 \\
\hline From Mar 2012 to Jul 2013 & 17 & -0.82 & -13.13 \\
\hline From Aug 2014 to Apr 2015 & 9 & -1.60 & -12.76 \\
\hline
\end{tabular}

greater-than-normal rainfall, droughts can emerge if storage is severely depleted. Evidence for such conditions is also observed within the periods 2003-04 and 2012-13 in the time series of SPI and WSDI computed for northwestern and peninsular India, respectively. In these time series, fluctuations in SPI are more responsive to monthly variations in rainfall. However, land water storage variations are much more continuous and of lower frequency even though they are primarily caused by variations in the hydrologic fluxes. This is because the land itself acts as an integrator of hydrologic fluxes and essentially behaves as a low-pass filter (Entekhabi and Rodriguez-Iturbe 1994).

Generally, the standardized deviations of GRACEderived TWS from its mean monthly climatology, which here we call the WSDI, captures well the major drought events over recent times in the Indian subcontinent. On average, about seven drought periods are observed in the four study regions discussed here. Among the major drought periods, the longest deficit period of 23 months (from February 2009 to December 2010) is observed in central India, with a peak deficit of $-135.8 \mathrm{~mm}$. The highest peak deficit of $-158.00 \mathrm{~mm}$ is observed in the month of January 2015 in central India. Results demonstrate that the major drought events of 2002 and 2004 are most prominent in peninsular, west-central, and northwestern India, whereas the drought of 2010 is conspicuous over central, west-central, and northwestern India. In all the four climatic zones the intensities of the identified drought events range from near normal to severe. No extreme drought events have been identified on the basis of WSDI.

In this study, drought appraisal as well as comparison with other indices has been performed utilizing monthly WSDI exclusively. However, accumulated values of WSDI have been utilized for severity analysis of drought events, which are identified by the persistence of negative WSDI values for three or more consecutive months. This assumption is based on the consideration persistence in the autocorrelation function of TWSA time series. Comparison between WSDI and other commonly used drought indices shows the strongest correlation 

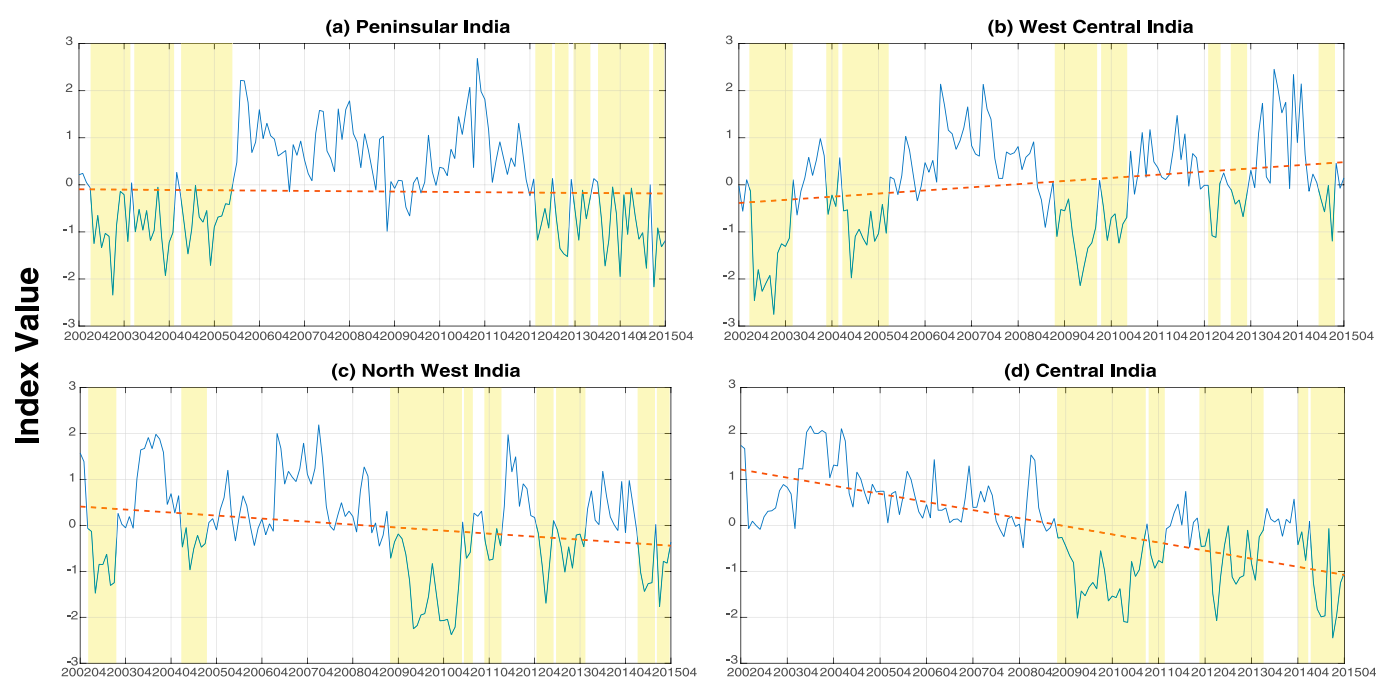

Time (Month)

Drought Periods— WSDI " . . Trendline

FIG. 5. Time series of WSDI (blue lines) and fitted trend lines (red dashed lines) for each of the four homogeneous rainfall regions of India.

with PDSI and the weakest with SPEI. This agreement is probably due to the concurrence of relevant hydrologic parameters directly or indirectly involved in their formulation. The estimated values of correlation between WSDI and PDSI for peninsular, west-central, northwestern, and central India are 0.76, 0.55, 0.48, and 0.70, respectively. In peninsular, west-central, northwestern, and central India, the highest severities of the respective climatic zones are $-10.35,-17.44,-26.31$, and -26.14 . Severity analyses suggest that among all the drought events observed in the four climatic zones, the drought event of 2009-10 is the most extensive and had primarily affected northwestern and central India. An overall increasing trend of $0.07 \mathrm{yr}^{-1}$ in WSDI is observed in westcentral India, while northwestern and central India experienced a decreasing trend of -0.07 and $-0.18 \mathrm{yr}^{-1}$, respectively. No significant trend in WSDI is observed in peninsular India. Trend analysis depicted deteriorating water-stressed conditions in northwestern and central India and improving water-sufficient conditions in west-central India. It is also important to note that, in India, there is no existing network or platform for real-time monitoring of drought like the U.S. Drought Monitor (http:// droughtmonitor.unl.edu), which could have been utilized as a standard of reference. Droughts in India are mostly reported on the basis of percentile of rainfall and at times even by visual drying of land surface (Gore et al. 2010).

WSDI exhibits significant advantages over the other indices. The proposed index is based on the deviations of TWS from normal conditions, which seems to be a more intuitive approach as it refrains from complicated numerical and statistical computations. Moreover, WSDI is more inclusive as it integrates hydrologic fluxes as well as the changes in storage. Additionally, computations of TWSD also provide direct means for quantifying changes in water storage, including the water required to satisfy the deficit at any moment in time and to restore regional wetness conditions to the normal range for that time of year. On the contrary, other indices rely on storage variables and hydrologic fluxes separately, often disregarding the contribution of one or the other. Say, for example, lack of rainfall over a particular area does not directly impact the vegetation or water availability if there is an ample antecedent storage of water. However, it is unlikely that prolonged deficit in TWS over a particular region will be recovered by normal rainfall for that region. Indices using surface meteorological variables or indices based on soil moisture that only account for a few centimeters are thereby incompetent to apprehend these internal dynamics. Furthermore, variations in TWS in terms of WSDI are more gradual and relate effectively with developing drought condition and are not episodic like precipitation or runoff events. This makes WSDI a more physically meaningful metric. There are, however, certain

TABLE 5. Estimates of annual trend in WSDI, along with their significance ( $p$ values) computed for the four homogenous rainfall regions of India.

\begin{tabular}{lcc}
\hline \hline & Trend $\left(\mathrm{yr}^{-1}\right)$ & Significance $(p$ value $)$ \\
\hline Peninsular India & 0.00 & 0.78 \\
West-central India & 0.07 & 0.027 \\
Northwestern India & -0.07 & $\ll 0.05$ \\
Central India & -0.18 & $\ll 0.05$ \\
\hline
\end{tabular}


limitations of using WSDI. Since it is entirely based on GRACE-observed TWS variations, limitations of GRACE pervade into WSDI estimates. For example, by itself GRACE cannot isolate contributions of various hydrologic stores toward monthly estimates of TWS. Further, WSDI is only effective over large spatial scales. This is because the accuracy of TWS estimates from GRACE tends to decrease markedly when considered over smaller regions (Landerer and Swenson 2012). However, errors in WSDI estimates can emerge because of the application of spatial filters and associated GRACE errors.

Overall, our results show that the severity as well as the length of drought period coincides well with the major, regional meteorological droughts reported in India. Recent drought events over four homogenous rainfall regions of India are well identified and quantified using WSDI for a period of 157 months (from April 2002 to April 2015).There are some noted differences in the drought characterized by WSDI and other commonly used drought indices. While WSDI is almost entirely based on integrated land water storage variations observed from space, other drought indices are dependent on hydrologic fluxes. The consideration of land water storage filters out the dependence on high-frequency variations of hydrologic fluxes and can thus be considered as a robust criterion for the characterization of drought. The WSDI shows promise for comprehensive drought monitoring regional drought events at the global scale. The methodology presented here is expected to produce improved results as acquisition and precision of GRACE data continues to improve, in particular as the time period of the GRACE and GRACE follow-on (Famiglietti and Rodell 2013) observations lengthens.

Acknowledgments. We thank the Department of Science and Technology, Ministry of Science and Technology, Government of India for providing the funding for this research under the Fast Track Programme [Project SR/FTP/ES-176/2010(G)]. The support of the NASA GRACE Science Team is gratefully acknowledged. This work was partially funded by grants from the University of California Office of the President, Multicampus Research Programs and Initiatives (JSF), by the NASA GRACE Science Team (JSF and JTR), and by the Jet Propulsion Laboratory Research and Technology Development program (JSF). A portion of this work was conducted at the Jet Propulsion Laboratory, operated under contract with NASA by the California Institute of Technology.

\section{REFERENCES}

Adler, R. F., and Coauthors, 2003: The version-2 Global Precipitation Climatology Project (GPCP) monthly precipitation analysis (1979-present). J. Hydrometeor., 4, 1147-1167, doi:10.1175/ 1525-7541(2003)004<1147:TVGPCP > 2.0.CO;2.

Agboma, C. O., S. Z. Yirdaw, and K. R. Snelgrove, 2009: Intercomparison of the total storage deficit index (TSDI) over two Canadian Prairie catchments. J. Hydrol., 374, 351-359, doi:10.1016/j.jhydrol.2009.06.034.

Beguería, S., S. M. Vicente-Serrano, and M. Angulo-Martínez, 2010: A multiscalar global drought dataset: The SPEI base: A new gridded product for the analysis of drought variability and impacts. Bull. Amer. Meteor. Soc., 91, 1351-1356, doi:10.1175/2010BAMS2988.1.

Bhalme, H. N., and D. A. Mooley, 1980: Large-scale droughts/floods and monsoon circulation. Mon. Wea. Rev., 108, 1197-1211, doi:10.1175/1520-0493(1980)108<1197:LSDAMC>2.0.CO;2.

Bhuiyan, C., R. P. Singh, and F. N. Kogan, 2006: Monitoring drought dynamics in the Aravalli region (India) using different indices based on ground and remote sensing data. Int. J. Appl. Earth Obs. Geoinf., 8, 289-302, doi:10.1016/j.jag.2006.03.002.

Castle, S. L., B. F. Thomas, J. T. Reager, M. Rodell, S. C. Swenson, and J. S. Famiglietti, 2014: Groundwater depletion during drought threatens future water security of the Colorado River basin. Geophys. Res. Lett., 41, 5904-5911, doi:10.1002/2014GL061055.

Chen, J. L., M. Rodell, C. R. Wilson, and J. S. Famiglietti, 2005a: Low degree spherical harmonic influences on Gravity Recovery and Climate Experiment (GRACE) water storage estimates. Geophys. Res. Lett., 32, L14405, doi:10.1029/ 2005GL022964.

, C. R. Wilson, B. D. Tapley, J. S. Famiglietti, and M. Rodell, 2005b: Seasonal global mean sea level change from satellite altimeter, GRACE, and geophysical models. J. Geod., 79, 532-539, doi:10.1007/s00190-005-0005-9.

,,--- Z. L. Yang, and G. Y. Niu, 2009: 2005 drought event in the Amazon River basin as measured by GRACE and estimated by climate models. J. Geophys. Res., 114, B05404, doi:10.1029/2008JB006056.

Chowdhury, A. M., M. Dandekar, and P. S. Raut, 1989: Variability in drought incidence over India-A statistical approach. Mausam, 40, 207-214.

Cook, B. I., R. L. Miller, and R. Seager, 2009: Amplification of the North American "Dust Bowl" drought through humaninduced land degradation. Proc. Natl. Acad. Sci. USA, 106, 4997-5001, doi:10.1073/pnas.0810200106.

Cook, E. R., R. Seager, M. A. Cane, and D. W. Stahle, 2007: North American drought: Reconstructions, causes, and consequences. Earth Sci. Rev., 81, 93-134, doi:10.1016/j.earscirev.2006.12.002.

Dai, A., 2011: Characteristics and trends in various forms of the Palmer drought severity index during 1900-2008. J. Geophys. Res., 116, D12115, doi:10.1029/2010JD015541.

, 2013: Increasing drought under global warming in observations and models. Nat. Climate Change, 3, 52-58, doi:10.1038/ nclimate1633.

— , P. J. Lamb, K. E. Trenberth, M. Hulme, P. D. Jones, and P. Xie, 2004: The recent Sahel drought is real. Int. J. Climatol., 24, 1323-1331, doi:10.1002/joc.1083.

Damberg, L., and A. AghaKouchak, 2014: Global trends and patterns of drought from space. Theor. Appl. Climatol., 117, 441-448, doi:10.1007/s00704-013-1019-5.

Entekhabi, D., and I. Rodriguez-Iturbe, 1994: Analytical framework for the characterization of space-time variability of soil moisture. Adv. Water Resour., 17, 35-45, doi:10.1016/0309-1708(94)90022-1.

Famiglietti, J. S., 2014: The global groundwater crisis. Nat. Climate Change, 4, 945-948, doi:10.1038/nclimate2425.

, and M. Rodell, 2013: Water in the balance. Science, 340, 1300-1301, doi:10.1126/science. 1236460. 
and Coauthors, 2011: Satellites measure recent rates of groundwater depletion in California's Central Valley. Geophys. Res. Lett., 38, L03403, doi:10.1029/2010GL046442.

Francis, P. A., and S. Gadgil, 2010: Towards understanding the unusual Indian monsoon in 2009. J. Earth Syst. Sci., 119, 397415, doi:10.1007/s12040-010-0033-6.

Frappart, F., F. Papa., J. S. da Silva, G. Ramillien, C. Prigent, F. Seyler, and S. Calmant, 2012: Surface freshwater storage and dynamics in the Amazon basin during the 2005 exceptional drought. Environ. Res. Lett., 7, 044010, doi:10.1088/ 1748-9326/7/4/044010.

Gadgil, S., P. N. Vinayachandran, and P. A. Francis, 2003: Droughts of the Indian summer monsoon: Role of clouds over the Indian Ocean. Curr. Sci., 85 (12), 1713-1719.

Ganguli, P., and M. J. Reddy, 2014: Evaluation of trends and multivariate frequency analysis of droughts in three meteorological subdivisions of western India. Int. J. Climatol., 34, 911-928, doi:10.1002/joc.3742.

Golian, S., O. Mazdiyasni, and A. AghaKouchak, 2015: Trends in meteorological and agricultural droughts in Iran. Theor. Appl. Climatol., 119, 679-688, doi:10.1007/s00704-014-1139-6.

Gore, P. G., T. Prasad, and H. R. Hatwar, 2010: Mapping of drought areas over India. NCC Research Rep. 12, National Climate Centre, Indian Meteorological Department, 25 pp. [Available online at http://www.imdpune.gov.in/Clim_Pred_ LRF_New/Reports/NCCResearchReports/research_report_ 12.pdf.]

Gregory, S., 1989: The changing frequency of drought in India, 1871-1985. Geogr. J., 155, 322-334, doi:10.2307/635207.

Guhathakurta, P., 2003: Drought in districts of India during the recent all India normal monsoon years and its probability of occurrence. Mausam, 54, 542-545.

Hamed, K. H., and A. R. Rao, 1998: A modified Mann-Kendall trend test for autocorrelated data. J. Hydrol., 204, 182-196, doi:10.1016/S0022-1694(97)00125-X.

Hao, Z., and A. AghaKouchak, 2014: A nonparametric multivariate multi-index drought monitoring framework. J. Hydrometeor., 15, 89-101, doi:10.1175/JHM-D-12-0160.1.

Heim, R. R., 2000: Drought indices: A review. Drought: A Global Assessment, Routledge, 159-167.

, 2002: A review of twentieth century drought indices used in the United States. Bull. Amer. Meteor. Soc., 83, 1149-1165, doi:10.1175/1520-0477(2002)083<1149:AROTDI>2.3.CO;2.

Hoerling, M., J. Eischeid, A. Kumar, R. Leung, A. Mariotti, K. Mo, S. Schubert, and R. Seager, 2014: Causes and predictability of the 2012 Great Plains drought. Bull. Amer. Meteor. Soc., 95, 269-282, doi:10.1175/BAMS-D-13-00055.1.

Houborg, R., M. Rodell, B. Li, R. Reichle, and B. F. Zaitchik, 2012: Drought indicators based on model-assimilated Gravity Recovery and Climate Experiment (GRACE) terrestrial water storage observations. Water Resour. Res., 48, W07525, doi:10.1029/2011WR011291.

Hoyos, C. D., and P. J. Webster, 2007: The role of intraseasonal variability in the nature of Asian monsoon precipitation. J. Climate, 20, 4402-4424, doi:10.1175/JCLI4252.1.

Huang, S., J. Chang, Q. Huang, and Y. Chen, 2014: Spatio-temporal changes and frequency analysis of drought in the Wei River Basin, China. Water Resour. Manage., 28, 3095-3110, doi:10.1007/s11269-014-0657-4.

Jain, S. K., R. Keshri, A. Goswami, and A. Sarkar, 2010: Application of meteorological and vegetation indices for evaluation of drought impact: A case study for Rajasthan, India. Nat. Hazards, 54, 643-656, doi:10.1007/s11069-009-9493-x.
Kendall, M. G., 1955: Rank Correlation Methods. Griffin, 196 pp.

Keyantash, J. A., and J. A. Dracup, 2002: The quantification of drought: An evaluation of drought indices. Bull. Amer. Meteor. Soc., 83, 1167-1180, doi:10.1175/1520-0477(2002)083<1191: TQODAE $>2.3 . \mathrm{CO} ; 2$

—, and —, 2004: An aggregate drought index: Assessing drought severity based on fluctuations in the hydrologic cycle and surface water storage. Water Resour. Res., 40, W09304, doi:10.1029/2003WR002610.

Kwak, J., Y. Kim, J. Lee, and H. Kim, 2012: Analysis of drought characteristics using copula theory. World Environmental and Water Resources Congress 2012, ASCE, 1762-1771, doi:10.1061/ 9780784412312.175.

Landerer, F. W., and S. C. Swenson, 2012: Accuracy of scaled GRACE terrestrial water storage estimates. Water Resour. Res., 48, W04531, doi:10.1029/2011WR011453.

Leblanc, M. J., P. Tregoning, G. Ramillien, S. O. Tweed, and A. Fakes, 2009: Basin-scale, integrated observations of the early 21st century multiyear drought in southeast Australia. Water Resour. Res., 45, W04408, doi:10.1029/2008WR007333.

Long, D., B. R. Scanlon, L. Longuevergne, A. Y. Sun, D. N. Fernando, and H. Save, 2013: GRACE satellite monitoring of large depletion in water storage in response to the 2011 drought in Texas. Geophys. Res. Lett., 40, 3395-3401, doi:10.1002/grl.50655.

Lorenz, C., H. Kunstmann, B. Devaraju, M. Tourian, N. Sneeuw, and J. Riegger, 2014: Large-scale runoff from landmasses: A global assessment of the closure of the hydrological and atmospheric water balances. J. Hydrometeor., 15, 2111-2139, doi:10.1175/JHM-D-13-0157.1.

Mann, H. B., 1945: Nonparametric tests against trend. Econometrica, 13, 245-259, doi:10.2307/1907187.

McKee, T. B., N. J. Doesken, and J. Kleist, 1993: The relationship of drought frequency and duration to time scales. Proc. Eighth Conf. on Applied Climatology, Anaheim, CA, Amer. Meteor. Soc., 17-22.

Mishra, A. K., and V. R. Desai, 2005a: Spatial and temporal drought analysis in the Kansabati River basin, India. Int. J. River Basin Manage., 3, 31-41, doi:10.1080/15715124.2005.9635243.

— Stochastic Environ. Res. Risk Assess., 19, 326-339, doi:10.1007/ s00477-005-0238-4

_ , and V. P. Singh, 2009: Analysis of drought severity-areafrequency curves using a general circulation model and scenario uncertainty. J. Geophys. Res., 114, D06120, doi:10.1029/ 2008JD010986.

— , and - 2010: A review of drought concepts. J. Hydrol., 391, 202-216, doi:10.1016/j.jhydrol.2010.07.012.

—, V. R. Desai, and V. P. Singh, 2007: Drought forecasting using a hybrid stochastic and neural network model. J. Hydrol. Eng., 12, 626-638, doi:10.1061/(ASCE)1084-0699(2007)12:6(626).

— V. P. Singh, and V. R. Desai, 2009: Drought characterization: A probabilistic approach. Stochastic Environ. Res. Risk Assess., 23, 41-55, doi:10.1007/s00477-007-0194-2.

Mo, K. C., 2008: Model-based drought indices over the United States. J. Hydrometeor., 9, 1212-1230, doi:10.1175/2008JHM1002.1.

_ 2011: Drought onset and recovery over the United States. J. Geophys. Res., 116, 1-14, doi:10.1029/2011JD016168.

Mu, Q., M. Zhao, J. S. Kimball, N. G. McDowell, and S. W. Running, 2013: A remotely sensed global terrestrial drought severity index. Bull. Amer. Meteor. Soc., 94, 83-98, doi:10.1175/ BAMS-D-11-00213.1.

Naresh Kumar, M. N., C. S. Murthy, M. V. R. Sesha Sai, and P. S. Roy, 2009: On the use of standardized precipitation index 
(SPI) for drought intensity assessment. Meteor. Appl., 16, 381389, doi:10.1002/met.136.

Neena, J. M., E. Suhas, and B. N. Goswami, 2011: Leading role of internal dynamics in the 2009 Indian summer monsoon drought. J. Geophys. Res., 116, D13103, doi:10.1029/2010JD015328.

NRAA, 2013: Contingency and compensatory agriculture plans for droughts and floods in India-2012. Position Paper 6, National Rainfed Area Authority, 87 pp. [Available online at http:// nraa.gov.in/pdf/Droughts\%20and\%20Floods\%20in\%20India2012.pdf.]

Palmer, W., 1965: Meteorological drought. U.S. Weather Bureau Research Paper 45, 58 pp. [Available online at http://www. ncdc.noaa.gov/temp-and-precip/drought/docs/palmer.pdf.]

Pandey, R. P., and K. S. Ramasastri, 2001: Relationship between the common climatic parameters and average drought frequency. Hydrol. Processes, 15, 1019-1032, doi:10.1002/hyp.187.

Parthasarathy, B., N. A. Sontakke, A. A. Monot, and D. R. Kothawale, 1987: Droughts/floods in the summer monsoon season over different meteorological subdivisions of India for the period 18711984. J. Climatol., 7, 57-70, doi:10.1002/joc.3370070106.

Rajeevan, M., J. Bhate, and A. K. Jaswal, 2008: Analysis of variability and trends of extreme rainfall events over India using 104 years of gridded daily rainfall data. Geophys. Res. Lett., 35, L18707, doi:10.1029/2008GL035143.

Reager, J. T., and J. S. Famiglietti, 2009: Global terrestrial water storage capacity and flood potential using GRACE. Geophys. Res. Lett., 36, L23402, doi:10.1029/2009GL040826.

_ B. B. Thomas, and J. S. Famiglietti, 2014: River basin flood potential inferred using GRACE gravity observations at several months lead time. Nat. Geosci., 7, 588-592, doi:10.1038/ ngeo2203.

Richey, A. S., B. F. Thomas, M.-H. Lo, J. S. Famiglietti, S. Swenson, and M. Rodell, 2015a: Uncertainty in global groundwater storage estimates in a total groundwater stress framework. Water Resour. Res., 51, 5198-5216, doi:10.1002/ 2015WR017351.

,$--\longrightarrow$, J. T. Reager, J. S. Famiglietti, K. Voss, S. Swenson, and M. Rodell, 2015b: Quantifying renewable groundwater stress with GRACE. Water Resour. Res., 51, 5217-5238, doi:10.1002/2015WR017349.

Rodell, M., and Coauthors, 2004: The Global Land Data Assimilation System. Bull. Amer. Meteor. Soc., 85, 381-394, doi:10.1175/ BAMS-85-3-381.

—_ I. Velicogna, and J. S. Famiglietti, 2009: Satellite-based estimates of groundwater depletion in India. Nature, 460, 999 1002, doi:10.1038/nature 08238 .

— D. P. Chambers, and J. S. Famiglietti, 2011: Groundwater and terrestrial water storage [in "State of the Climate in 2010"]. Bull. Amer. Meteor. Soc., 92 (6), S49-S52.

Samra, J., 2004: Review and analysis of drought monitoring, declaration and management in India. Working Paper 84, International Water Management Institute, 40 pp. [Available online at http://www.preventionweb.net/files/1868_ VL102135.pdf.]

Sen, P. K., 1968: Estimates of the regression coefficient based on Kendall's tau. J. Amer. Stat. Assoc., 63, 1379-1389, doi:10.1080/ 01621459.1968.10480934.

Shukla, S., and A. Wood, 2008: Use of a standardized runoff index for characterizing hydrologic drought. Geophys. Res. Lett., 35, L02405, doi:10.1029/2007GL032487.

Sikka, D. R., 2003: Evaluation of monitoring and forecasting of summer monsoon over India and are view of monsoon drought of 2002. Proc. Natl. Acad. Sci. India, A69, 479-504.
Singh, R. P., S. Roy, and F. Kogan, 2003: Vegetation and temperature condition indices from NOAA AVHRR data for drought monitoring over India. Int. J. Remote Sens., 24, 43934402, doi:10.1080/0143116031000084323.

Sinha Ray, K. C., and M. P. Shewale, 2001: Probability of occurrence of drought in various subdivisions of India. Mausam, 52, 541-546.

Sivakumar, M. V. K., D. A. Wilhite, R. P. Motha, and D. A. Wood, Eds., 2011: Agricultural drought indices: Proceedings of an expert meeting. AGM-11, WMO/TD-1572, WAOB-2011, World Meteorological Organization, 197 pp. [Available online at http://www.wamis.org/agm/pubs/agm11/agm11.pdf.]

Soni, A., and T. H. Syed, 2015: Diagnosing land water storage variations in major Indian river basins using GRACE observations. Global Planet. Change, 133, 263-271, doi:10.1016/ j.gloplacha.2015.09.007.

Strassberg, G., B. R. Scanlon, and M. Rodell, 2007: Comparison of seasonal terrestrial water storage variations from GRACE with groundwater-level measurements from the High Plains Aquifer (USA). Geophys. Res. Lett., 34, L14402, doi:10.1029/ 2007GL030139.

Swenson, S., and J. Wahr, 2006: Post-processing removal of correlated errors in GRACE data. Geophys. Res. Lett., 33, L08402, doi:10.1029/2005GL025285.

Syed, T. H., J. S. Famiglietti, V. Zlotnicki, and M. Rodell, 2007: Contemporary estimates of Pan-Arctic freshwater discharge from GRACE and reanalysis. Geophys. Res. Lett., 34, L19404, doi:10.1029/2007GL031254.

,,-- M. Rodell, J. Chen, and C. R. Wilson, 2008: Analysis of terrestrial water storage changes from GRACE and GLDAS. Water Resour. Res., 44, W02433, doi:10.1029/2006WR005779. , ——, and D. P. Chambers, 2009: GRACE-based estimates of terrestrial freshwater discharge from basin to continental scales. J. Hydrometeor., 10, 22-40, doi:10.1175/2008JHM993.1.

$-, \ldots,-$, J. K. Willis, and K. Hilburn, 2010: Satellite-based global-ocean mass balance estimates of interannual variability and emerging trends in continental freshwater discharge. Proc. Natl. Acad. Sci. USA, 107, 17916-17921, doi:10.1073/ pnas.1003292107.

_, P. J. Webster, and J. S. Famiglietti, 2014: Assessing variability of evapotranspiration over the Ganga River basin using water balance computations. Water Resour. Res., 50, 2551-2565, doi:10.1002/2013WR013518.

Tang, J., H. Cheng, and L. Liu, 2014: Assessing the recent droughts in southwestern China using satellite gravimetry. Water Resour. Res., 50, 3030-3038, doi:10.1002/2013WR014656.

Tapley, B. D., S. Bettadpur, J. C. Ries, P. F. Thompson, and M. M. Watkins, 2004: GRACE measurements of mass variability in the earth system. Science, 305, 503-505, doi:10.1126/science.1099192.

Thomas, A. C., J. T. Reager, J. S. Famiglietti, and M. Rodell, 2014: A GRACE-based water storage deficit approach for hydrological drought characterization. Geophys. Res. Lett., 41, 1537-1545, doi:10.1002/2014GL059323.

Tiwari, V. M., J. Wahr, and S. Swenson, 2009: Dwindling groundwater resources in northern India, from satellite gravity observations. Geophys. Res. Lett., 36, L18401, doi:10.1029/ 2009 GL039401.

van Dijk, A. I., H. E. Beck, R. S. Crosbie, R. A. M. Jeu, Y. Y. Liu, G. M. Podger, B. Timbal, and N. R. Viney, 2013: The Millennium Drought in southeast Australia (2001-2009): Natural and human causes and implications for water resources, ecosystems, economy, and society. Water Resour. Res., 49, 10401057, doi:10.1002/wrcr.20123. 
Velicogna, I., 2009: Increasing rates of ice mass loss from the Greenland and Antarctic ice sheets revealed by GRACE. Geophys. Res. Lett., 36, L19503, doi:10.1029/2009GL040222.

Vicente-Serrano, S., M. S. Beguería, and J. I. López-Moreno, 2010a: A multiscalar drought index sensitive to global warming: The standardized precipitation evapotranspiration index. J. Climate, 23, 1696-1718, doi:10.1175/2009JCLI2909.1.

,,,--- M. Angulo, and A. El Kenawy, 2010b: A new global $0.5^{\circ}$ gridded dataset (1901-2006) of a multiscalar drought index: Comparison with current drought index datasets based on the Palmer drought severity index. J. Hydrometeor., 11, 1033-1043, doi:10.1175/2010JHM1224.1.

Voss, K. A., J. S. Famiglietti, M. Lo, C. De Linage, M. Rodell, and S. C. Swenson, 2013: Groundwater depletion in the Middle East from GRACE with implications for transboundary water management in the Tigris-Euphrates-western Iran region. Water Resour. Res., 49, 904-914, doi:10.1002/wrcr.20078.

Wahr, J., S. Swenson, V. Zlotnicki, and I. Velicogna, 2004: Timevariable gravity from GRACE: First results. Geophys. Res. Lett., 31, L11501, doi:10.1029/2004GL019779.

Wells, N., S. Goddard, and M. J. Hayes, 2004: A self-calibrating Palmer drought severity index. J. Climate, 17, 2335-2351, doi:10.1175/1520-0442(2004)017<2335:ASPDSI>2.0.CO;2.

Wilhite, D. A., 2000: Drought as a natural hazard: Concepts and definitions. Droughts: A Global Assessment, Routledge, 3-18.
_ 2006: Drought monitoring, mitigation and preparedness in the United States: An end to end approach. WMO Task Force on Socio-Economic Application of Public Weather Services, Geneva, Switzerland, WMO, $32 \mathrm{pp}$. [Available online at https://www.wmo.int/pages/prog/amp/pwsp/documents/ Wilhite_WMO_Drought_PWS.pdf.]

Yevjevich, V., 1967: An objective approach to definitions and investigations of continental hydrologic droughts. Hydrology Paper 23, Colorado State University, 25 pp. [Available online at https://dspace.library.colostate.edu/ bitstream/handle/10217/61303/HydrologyPapers_n23.pdf? sequence $=1$.]

Yirdaw, S. Z., K. R. Snelgrove, and C. O Agboma, 2008: GRACE satellite observations of terrestrial moisture changes for drought characterization in the Canadian Prairie. J. Hydrol., 356, 84-92, doi:10.1016/j.jhydrol.2008.04.004.

Zeng, Z., S. Piao, X. Lin, G. Yin, S. Peng, P. Ciais, and R. B. Myneni, 2012: Global evapotranspiration over the past three decades: Estimation based on the water balance equation combined with empirical models. Environ. Res. Lett., 7, 014026, doi:10.1088/1748-9326/7/1/014026.

Zhang, D., Q. Zhang, A. D. Werner, and X. Liu, 2016: GRACEbased hydrological drought evaluation of the Yangtze River basin, China. J. Hydrometeor., 17, 811-828, doi:10.1175/ JHM-D-15-0084.1. 